\title{
Aspectos da comunicação da enfermeira com o deficiente auditivo*
}

\author{
ASPECTS OF NURSES' COMMUNICATION WITH HEARING IMPAIRED PERSONS \\ ASPECTOS DE LA COMUNICACIÓN DE LA ENFERMERA CON EL DEFICIENTE AUDITIVO
}

\section{Lorita Marlena Freitag Pagliuca', Nara Lígia Gregório Fiúza², Cristiana Brasil de Almeida Rebouças ${ }^{3}$}

\begin{abstract}
RESUMO
Indivíduos com limitação auditiva têm seu processo comunicativo prejudicado. Procurou-se explorar aspectos da comunicação da enfermeira com os deficientes auditivos. Estudo descritivo-exploratório, realizado em hospitais de Fortaleza de maio a junho de 2004 mediante entrevistas abertas analisadas qualitativamente. As enfermeiras percebem que é difícil a comunicação com o deficiente auditivo, embora algumas tenham desempenho satisfatório. Nesse processo, algumas referem utilizar tanto a comunicação não-verbal, por mímica e leitura labial, como a comunicação verbal oral e escrita. Outras utilizam o acompanhante, quebrando o sigilo da consulta. Para aperfeiçoar a comunicação, sugere-se o preparo profissional na graduação e cursos de LIBRAS. Conforme se conclui, existe dificuldade da enfermeira ao se comunicar com o deficiente auditivo.
\end{abstract}

\section{DESCRITORES}

Comunicação.

Enfermagem.

Surdez.

Perda auditiva.

Pessoas com insuficiência auditiva.

\begin{abstract}
The communicative process of individuals with hearing limitation is jeopardized. This article is aimed at exploring nurses' communication aspects with hearing impaired persons. It is a descriptiveexploratory study conducted in hospitals in Fortaleza, State of Ceará, from May to June of 2004 through open interviews that were analyzed qualitatively. The nurses perceived communication with hearing impaired persons as difficult, although some had a satisfactory performance. In the process, some mention the use of both nonverbal communication, such as mimics and lip reading, and verbal oral and written communication. Others resorted to the person that accompanies the patient, thus breaking the confidentiality of the consultation. To enhance communication, professional preparation in the undergraduate course and through Libras courses is suggested. The conclusion is that it is difficult for nurses to communicate with hearing impaired persons.
\end{abstract}

\section{KEY WORDS}

Communication.

Nursing.

Deafness.

Hearing loss.

Hearing impaired persons.

\section{RESUMEN}

Individuos con limitación auditiva tienen su proceso comunicativo perjudicado. Se buscó explorar aspectos de la comunicación de la enfermera con los deficientes auditivos. Estudio descriptivo y exploratorio, realizado en hospitales de Fortaleza, de mayo a junio de 2004, mediante entrevistas abiertas analizadas cualitativamente. Las enfermeras notan que es difícil la comunicación con el deficiente auditivo, aunque algunas tengan desempeño satisfactorio. En ese proceso, algunas se han referido en utilizar tanto la comunicación no verbal, por mímica y lectura labial, como la comunicación verbal oral y escritura. Otras utilizan el acompañante, rompiendo el sigilo de la consulta. Para perfeccionar la comunicación, se sugiere el preparo profesional en la graduación y cursos de LIBRAS. Conforme se concluye, existe dificultad de la enfermera para comunicarse con el deficiente auditivo.

\section{DESCRIPTORES}

Comunicación.

Enfermería.

Sordera.

Pérdida auditiva.

Personas con deficiência auditiva.

\footnotetext{
* Extraído da monografia de conclusão de Curso de Enfermagem, Universidade Federal do Ceará (UFC), Projeto Acessibilidade aos Serviços de Saúde/MS/ FUNCAP.

1 Enfermeira. Professora Titular do Departamento de Enfermagem, UFC. Fortaleza, CE, Brasil. pagliuca@ufc.br

2 Enfermeira, graduada pela UFC. Fortaleza, $\mathrm{CE}$, Brasil. naralgf@hotmail.com 3 Enfermeira. Doutoranda do Programa de Pós-Graduação em Enfermagem, UFC. Fortaleza, CE, Brasil.

cristianareboucas@ yahoo.com.br
} 


\section{INTRODUÇÃO}

A expressão pessoa com necessidade especial é usada em referência a portadores de anomalias físicas, psíquicas, fisiológicas, além de outras de difícil caracterização ${ }^{(1)}$. Por deficiência, de modo geral, se define toda perda ou anormalidade de uma estrutura ou função psicológica, fisiológica ou anatômica ${ }^{(2)}$.

Pessoas com deficiência apresentam características próprias. Tais características, muitas vezes, as tornam vítimas de preconceitos ou excluídas da sociedade. Algumas se autoexcluem por se acharem inferiores. Outras se isolam das pessoas consideradas normais e procuram conviver com outro deficiente semelhante. Como observado, a limitação corporal ou mental pode afetar o comportamento e dar origem a aspectos ora atípicos, fortes e adaptativos, ora fracos e pouco funcionais ${ }^{(3)}$. Diante destes comportamentos, surgem dificuldades, principalmente de comunicação, e apesar das campanhas de educação para melhorar a inclusão dos deficientes, estes obstáculos persistem e se evidenciam ainda mais na comunicação com os deficientes auditivos e a população em geral.

A audição é o sentido por meio do qual se percebem os sons ${ }^{(4)}$. No caso dos deficientes auditivos, estes podem ser classificados em surdos totais e surdos parciais. O totalmente surdo é aquele em que a audição não é funcional na vida comum; e parcialmente surdo é aquele em que a audição, embora deficiente, é funcional, com ou sem prótese auditiva ${ }^{(5)}$. Esse tipo de deficiência é bastante freqüente, pois segundo estimativas da Organização Mundial de Saúde (OMS), cerca de $15 \%$ da população brasileira é portadora de alguma deficiência auditiva ${ }^{(2)}$.

A deficiência auditiva, foco deste estudo, é tratada por muitos autores como o tipo de deficiência de mais difícil convívio com o restante da sociedade. Ao se comparar as pessoas com deficiência física, auditiva e visual, o deficiente auditivo é o que enfrenta maior dificuldade de inclusão na sociedade, porquanto a audição é o sentido essencial para a aquisição e uso da linguagem. Em face da invisibilidade da sua limitação, muitas vezes este deficiente é estigmatizado como revoltado e dissimulado ${ }^{(6)}$.

A privação auditiva se configura como um grave distúrbio neurológico sensorial que afeta a capacidade de comunicação oral e de aprendizagem deste tipo de clientela. Ao enfermeiro, como profissional atuante na área da saúde, cabe avançar nos fundamentos básicos da Comunicação Total, considerada uma filosofia de trabalho voltada para o atendimento e educação das pessoas surdas, para assim entendê-las e assisti-las em suas necessidades humanas básicas ${ }^{(5)}$.
Por meio da comunicação estabelecida com o paciente, o profissional pode compreendê-lo como ser holístico, e perceber sua visão de mundo, isto é, seu modo de pensar, sentir e agir. Dessa forma, poderá entender as necessidades do paciente e, assim, prestar assistência adequada, minimizando seu sofrimento. Nesse processo, a comunicação ocupa espaço insubstituível e se ela não é efetiva esta assistência torna-se falha.

Portanto, particularmente neste caso, o instrumento básico de trabalho dos enfermeiros é a comunicação. Por isto, eles devem conhecer os princípios deste processo e desenvolver habilidades para estabelecer uma comunicação eficaz.

Enquanto as pessoas ouvintes demonstram o funcionamento normal da audição pela habilidade nos atos do ouvir e do falar, as pessoas surdas evidenciam-se em relação à norma por uma fala truncada, de difícil compreensão e um suporte gestual acentuado no ato da comunicação. Para aquele que ouve, a surdez representa uma perda da comunicação, a exclusão a partir do seu mundo ${ }^{(7)}$.

A linguagem utilizada pelos ouvintes comuns é a oral; a usada pelos surdos é a LIBRAS ou Língua Brasileira de Sinais. Entretanto, a língua oral e a língua de sinais não são línguas opostas e sim canais diferentes para a transmissão e a recepção de mensagens $^{(7)}$. Ante a dificuldade de comunicação dos surdos, surgiu a LIBRAS, com a finalidade de uniformizar os gestos emitidos pelos surdos no ato da comunicação.

Atualmente a LIBRAS é reconhecida cientificamente como um sistema lingüístico de comunicação gesto-visual, com estrutura gramatical própria, independente da língua portuguesa. Desse modo, os surdos utilizam as mãos, em combinação com braços, tórax, cabeça, e abordam qualquer tipo de assunto. Diversas temáticas podem ser alvo de discussão entre eles mesmos ou com pessoas de audição normal que dominem a língua de sinais. Cada país, porém, possui a sua própria língua de sinais, mas como a maioria destes se refere aos objetos e ao ser humano, existem alguns sinais comuns entre as diversas línguas do mundo ${ }^{(8)}$. Dessa maneira, a LIBRAS pode ser entendida como uma sistematização destes sinais, embora sob influência da cultura e do regionalismo no Brasil e em outros países.

Em nosso meio, a língua de sinais ainda é pouco difundida, até mesmo entre os deficientes auditivos, pois o número de instrutores é escasso e a literatura nesta linguagem é quase inexistente.

Somente pela comunicação efetiva poderá o profissional ajudar o paciente a conceituar seus problemas, enfrentá-los, demonstrar sua participação na experiência e encontrar 
alternativas para solucioná-los. Cabe à equipe, então, conhecer os mecanismos de comunicação que facilitarão o melhor desempenho de suas funções em relação ao paciente, bem como melhorar o relacionamento entre os próprios membros da equipe ${ }^{(9)}$.

No processo de comunicação, alguns elementos devem estar presentes. São eles: emissor, receptor, mensagem, canal e resposta. Portanto, a comunicação configura-se como uma forma de compreender e compartilhar mensagens enviadas e recebidas. O modo como se dá este intercâmbio exercerá influência no comportamento das pessoas envolvidas ${ }^{(10)}$. Para estabelecer relacionamento efetivo entre pessoas, o processo comunicativo torna-se importante, pois exerce influência no comportamento e é um instrumento para poder oferecer apoio, conforto e informação, como também despertar o sentimento de confiança e de auto-estima, considerados essenciais ao sucesso da comunicação e da realização pessoal e profissional ${ }^{(11)}$.

Com base nestas questões, os objetivos deste estudo foram identificar as dificuldades de comunicação da enfermeira com o surdo, as estratégias de comunicação que o profissional adotou, como também perceber o relacionamento com esta clientela e as sugestões para melhorar a comunicação entre enfermeiros e surdos.

\section{MÉTODO}

Estudo do tipo descritivo-exploratório, considerado exploratório quando um problema é pouco conhecido, ou seja, quando as hipóteses ainda não foram claramente definidas. Tal como a pesquisa descritiva, a pesquisa investigatória inicia-se por algum fenômeno de interesse; mas ao invés de, simplesmente, observar e registrar a incidência do fenômeno, a pesquisa exploratória busca explorar as dimensões desse fenômeno, a maneira pela qual se manifesta e outros fatores com os quais ele se relaciona $^{(12)}$.

A pesquisa foi realizada em quatorze hospitais da cidade de Fortaleza-CE, isto é, um terço do total existente, e a escolha foi aleatória por meio de sorteio, excluídos os serviços especializados. A seleção destes hospitais foi realizada em estudo anterior onde se avaliou a acessibilidade física e sensorial nos hospitais da cidade. Nesse estudo, de cunho quantitativo, o cálculo da amostra determinou que um terço dos hospitais já mostrariam dados significativos para a pesquisa. Com relação à exclusão de hospitais especializados devese ao fato de que nestes serviços as condições de acessibilidade já estão adequadas ao indivíduo com deficiência ${ }^{(13)}$. Quanto à população em estudo, foi composta por enfermeiros de Fortaleza, funcionários de hospitais gerais, enquanto a amostra resumiu-se a um enfermeiro de cada hospital selecionado. Esses enfermeiros foram selecionados por terem participado da pesquisa anterior.
A coleta de dados ocorreu nos meses de maio e junho de 2004, mediante roteiro de entrevista aberta que continha perguntas referentes às facilidades e dificuldades nas formas de comunicação com os deficientes auditivos; a percepção do relacionamento da enfermeira com o deficiente auditivo e as sugestões para melhorar o processo de comunicação. Os dados foram coletados até o momento que se percebeu repetição das informações.

As entrevistas foram gravadas, transcritas e analisadas qualitativamente pelo método de análise de conteúdo. Este é composto de um conjunto de técnicas de análise das comunicações, com vistas não ao estudo da língua ou da linguagem, mas sim à determinação mais ou menos parcial das condições de produção dos textos, que são o seu objeto ${ }^{(14)}$.

O estudo foi autorizado pelo Comitê de Ética em Pesquisa do Complexo Hospitalar da Universidade Federal do Ceará, pela Secretaria da Saúde do Estado e pelo coordenador ou diretor de cada hospital pesquisado. Obteve-se consentimento livre e esclarecido de cada enfermeiro e foram respeitados os princípios bioéticos postulados na resolução 196/96 do Conselho Nacional de Saúde ${ }^{(15)}$.

\section{RESULTADOS}

A coleta de dados foi realizada em quatorze hospitais da cidade de Fortaleza. Entre eles havia instituições públicas, particulares e filantrópicas. Em cada hospital foi entrevistada uma enfermeira. As idades variaram entre 22 e 59 anos e tempo de atuação profissional de 3 meses a 27 anos. Havia enfermeiros graduados, especialistas e mestres.

Com base nos dados, foram estabelecidas as seguintes categorias: Dificuldades de Comunicação; Estratégias de Comunicação, com as subcategorias comunicação não-verbal, comunicação verbal por meio da escrita e comunicação via acompanhante; Relacionamento Profissional, com as subcategorias dificuldade de relacionamento e relacionamento satisfatório; e Sugestões para melhorar a Comunicação entre os profissionais de enfermagem e as pessoas com deficiência auditiva.

Na categoria Dificuldades de Comunicação, as enfermeiras relataram o seguinte:

... as pessoas da área da saúde na sua carreira acadêmica não são preparadas para esse tipo de atendimento.(E 2)

... existe uma dificuldade muito grande, principalmente com o paciente surdo-mudo, pois ele sabe fazer a leitura labial, pra eu conseguir informação dele é bastante complicado... . (E 4)

... tem uma certa barreira, se o deficiente for auditivo, fica mais complicado... nem sempre a gente tem a formação de como transmitir informação para ele... . (E 5) 
...não estão muito acostumadas a lidar com os deficientes auditivos e nem de outras formas de deficiência... . (E 11)

Difícil, nós percebemos que não temos preparo para nos comunicarmos com o deficiente em geral, principalmente o auditivo. (E 14)

A categoria Estratégias de Comunicação se subdividiu em três subcategorias: comunicação não-verbal, comunicação verbal por meio da escrita e comunicação verbal via acompanhante, conforme se observa a seguir:

\section{Comunicação não-verbal}

Eu uso a mímica e falo bem devagar, pois assim o paciente lê os lábios da gente.... (E 1)

Uso a leitura labial... se o paciente não souber fazer a leitura labial a gente não consegue se comunicar (E 4)

... se for surdez total falo lento pra ele tentar ler meus lábios... . (E 5)

Uso mímica, gesto... . (E 7)

Eu procuro fazer gestos... mas, por ele não me ouvir, eu acho que ele não entende o gesto que eu estou fazendo... .(E 8)

Eu uso mímicas, mas não consigo entender o que eles querem transmitir para mim... . (E 14)

\section{Comunicação verbal por meio da escrita}

... eu uso a escrita... às vezes me ajuda a comunicar com esses pacientes... . (E 6)

... uso a escrita... Às vezes para entender o que o paciente quer falar eu coloco o alfabeto numa folha para o paciente ir apontando e montando palavras... . (E 11)

\section{Comunicação verbal via acompanhante}

Eu ia recorrer à família do paciente... . (E 9)

É bom ter um acompanhante que saiba transmitir o que o paciente está querendo dizer... .(E 13)

A categoria Relacionamento Profissional subdividiuse nas subcategorias dificuldade de relacionamento e relacionamento satisfatório. Os relatos foram os seguintes:

\section{Dificuldade de relacionamento}

O meu relacionamento é deficiente. Não sei muito como lidar com esse tipo de paciente... .(E 4)

Eu tento agir naturalmente, mas tenho um certo bloqueio, uma certa dificuldade para me relacionar com o deficiente auditivo....(E 5)

Eu encaro esse relacionamento com muitas dificuldades.. . (E 8) ...uma aflição muito grande quando tem esse tipo de paciente aqui, fico muito angustiada, não os entendo e nem eles me entendem, chamo outra pessoa para me ajudar.. . (E 14)

\section{Relacionamento satisfatório}

O nosso relacionamento tem sido da melhor maneira possível, dando apoio emocional e sempre proporcionando o bem-estar do cliente... . (E 1)

...sempre procuro ver a limitação do paciente, sabendo até onde eu posso explorar, só assim consigo realizar uma melhor assistência com esse tipo de paciente... . (E 2)

Meu relacionamento é muito bom, sou uma pessoa superdisposta... sempre estou aprendendo, ensinando, orientando os auxiliares para lidar com isso... . (E 9)

... aqui a gente se relaciona muito bem com esses pacientes, buscando melhorar esse processo a cada dia... . (E 11)

Já a última categoria, Sugestões para melhorar a Comunicação, as enfermeiras afirmaram o seguinte:

Eu acho que deveria ter um maior incentivo do Ministério da Saúde na realização de campanhas dentro dos hospitais, das universidades... .(E 1)

... deveria haver um curso de relações humanas, ou até mesmo uma reciclagem de todos os profissionais do hospital, sejam elas da saúde, da limpeza ou de qualquer setor. (E 3)

.. um treinamento, um curso de humanização hospitalar.. . (E 7)

Acho que a gente deveria ter um preparo... eu mesma deveria procurar um curso básico para suprir essa necessidade.... (E 8)

Eu acho que não há uma conscientização dos profissionais nem na época da faculdade, nem nos cursos de técnicos e auxiliares de enfermagem. (E 9)

Seriam necessárias palestras educativas e políticas públicas mais voltadas para essa deficiência... .(E 11)

Eu acho que o alfabeto dos surdos devia ser mais divulgado, ter cursos nas universidades, nos colégios... . $(E 2,4,13,14)$

\section{DISCUSSÃO}

Na primeira fase da entrevista foi avaliada a comunicação, considerada um processo de compreender, compartilhar idéias e sentimentos a fim de torná-los comuns aos participantes do processo comunicativo. Graças a essa habili- 
dade de comunicação, o homem enriquece o seu referencial de conhecimentos, satisfaz suas necessidades, transmite seus sentimentos e pensamentos, esclarece, interage e conhece o que os outros pensam e sentem ${ }^{(11)}$.

As enfermeiras foram questionadas sobre como percebem o processo de comunicação com os deficientes auditivos e quais os métodos utilizados para essa comunicação. Em relação à percepção do processo de comunicação, todas se enquadraram no grupo com dificuldade de comunicação. As enfermeiras mostraram-se inseguras ao se relacionarem com os surdos por não conhecerem a língua utilizada por eles, pela falta de habilidade em transmitir a informação sobre sua saúde, pela falta de formação durante a carreira acadêmica e até pela inexperiência.

Conforme se sabe, não se pode pensar em atuação profissional sem levar em conta a importância do processo comunicativo inerente à pratica assistencial ${ }^{(9)}$. Portanto, quando não há uma comunicação eficaz, não há como auxiliar o paciente a resolver seus problemas e minimizar conflitos. Segundo evidenciado, isso se torna mais sério no caso da comunicação com pacientes deficientes auditivos, pois estes, muitas vezes, se restringem a pessoas com as quais se relacionam habitualmente. Dessa forma, quando são hospitalizados, passam a conviver em ambiente estranho, com pessoas que não entendem sua forma de comunicação, em virtude de não terem uma habilidade específica para compreender a linguagem própria destes pacientes.

Ao se deparar com deficientes auditivos, percebem-se as dificuldades enfrentadas por este grupo para utilizar qualquer tipo de recurso disponível em nosso meio social. Percebe-se, também, quão dependentes estes se tornam do pouco que a enfermagem oferece, exatamente por não ter habilidade de comunicação total com esta clientela ${ }^{(16)}$.

$\mathrm{Na}$ maioria das vezes, ao recorrer aos profissionais da área da saúde, o surdo se defronta com a falta de domínio de comunicação por parte deste grupo. Dessa maneira, na opinião dos surdos, a saúde dos deficientes auditivos pode ser traduzida por descaso e desinteresse dos profissionais. Aparentemente é mais fácil tomar atitudes por eles do que lhes dar o direito de decidir o que é melhor para sua saúde ${ }^{(17)}$.

Entretanto, uma das dificuldades de comunicação dos enfermeiros com os deficientes auditivos advém da condição desta clientela, pois o comprometimento na aquisição e desenvolvimento da linguagem representa incalculável prejuízo, uma vez que modifica o processo de raciocínio e pensamento. Além dessa dificuldade de comunicação entre estes dois grupos, foi citado também o despreparo na formação acadêmica dos profissionais. Como nessa pesquisa exis- tem profissionais recém-formados até enfermeiras com 27 anos de profissão, de hospitais públicos, particulares e filantrópicos, imagina-se que esse despreparo é amplo e envolve a enfermagem em todos os níveis da profissão.

Já na segunda fase da entrevista, ainda sobre a categoria comunicação, indagou-se sobre as formas utilizadas para a comunicação entre os profissionais de enfermagem e os deficientes auditivos. A partir das indagações, encontraramse respostas que foram agrupadas em três subcategorias: comunicação não-verbal; comunicação verbal por meio da escrita; e comunicação verbal via acompanhante.

Existem várias maneiras de se comunicar com esse tipo de deficiente. No entanto, cada profissional utiliza a forma que considera mais eficaz no processo de comunicação. Nem sempre, porém, a forma utilizada pelo profissional é a melhor para a comunicação com o deficiente auditivo, pois o deficiente auditivo com surdez severa poderá ficar limitado, conforme o nível de escolaridade, ao uso de gestos isolados e próprios, entendidos exclusivamente no âmbito familiar ${ }^{(18)}$. Dessa forma, o profissional precisa adequar sua forma de comunicação de acordo com o paciente. Para isto, é necessário saber qual o nível de escolaridade do paciente e, a partir daí, qual a melhor forma para esta comunicação.

A comunicação não-verbal refere-se a mensagens enviadas por meio de ações e comportamentos humanos em vez de palavras, utilizados, na maior parte das mensagens enviadas e recebidas, pelas expressões faciais, maneirismos, voz, postura e vestimenta $^{(19)}$. Basicamente, os deficientes auditivos se comunicam de modo não-verbal, pois eles não conseguem oralizar as palavras. Entre os surdos, a comunicação não-verbal é usada de forma mais consciente e objetiva, com bom nível de interação em grupo. Na maioria das vezes, a linguagem dos surdos é gestual e global, ou seja, um único tipo de gesto pode significar uma idéia completa, como também alguns gestos podem comunicar uma única ação ${ }^{(8)}$.

Diante disso, pode-se concluir que a comunicação nãoverbal exerce maior influência em relação àquilo que se deseja exprimir e que as expressões e manifestações corporais são indispensáveis para ocorrer o processo comunicativo. A comunicação não-verbal tem expressão própria da cultura, do ambiente social onde vigora, assim como a LIBRAS. Esta, como já descrito, sofre influência da mesma forma. Ela transmite crenças, valores comuns a determinados povos ou mesmo a uma parcela da população. O que a comunicação não-verbal não domina é o mundo interior do destinatário, que interpreta, modifica, reinventa a mensagem, porquanto este destinatário está inserido em uma cultura própria e pode manipular esse tipo de comunicação ${ }^{(19)}$. 
Para captar as mensagens, os enfermeiros devem ser hábeis, no intuito de interpretá-las e potenciá-las criativamente, pois quanto maior for a capacidade de decodificar o não-verbal, maiores serão suas condições de emitir adequadamente os sinais não-verbais, ser coerente com o paciente, compreendê-lo e comunicar-se com este, para, então, estabelecer um plano de cuidados adequado de acordo com as necessidades dele ${ }^{(9)}$. Alguns autores enfatizam a importância do processo de comunicação não-verbal para a efetivação da comunicação em geral. A partir daí, pode-se perceber esta importância, principalmente para pacientes que não conseguem ouvir ou emitir palavras e que dependem diretamente desse tipo de comunicação para entenderem ou serem entendidos.

Como evidenciado, as formas de comunicação não-verbal mais utilizadas foram a leitura labial, os gestos e as mímicas, porém nem sempre o processo da comunicação tem sucesso, ou seja, nem sempre é entendido por ambas as partes. Muitas vezes, o paciente não consegue fazer a leitura labial, ou o profissional não consegue entender as mímicas ou os gestos feitos por ele. Ou seja, os métodos nem sempre são claros, e mostram-se eficazes somente quando se trata de mensagens curtas. Outra desvantagem é que essa forma de comunicação demanda tempo e esforço do enfermeiro e do paciente.

Portanto, uma das formas de comunicação com o deficiente auditivo possível de sucesso seria a linguagem de sinais, considerada um elemento muito valioso para a comunidade dos surdos, e também um instrumento muito útil para educadores, para a família do surdo e para outros profissionais ${ }^{(5)}$. Porém, conforme visto, apenas um dos profissionais entrevistados citou esse método de comunicação com o deficiente auditivo. Segundo se sabe, tal método requer treinamento tanto da equipe quanto do próprio deficiente. Ficou evidente que nenhum destes profissionais foi treinado ou conhece essa linguagem.

Outra forma de comunicação com deficientes auditivos mencionada foi a escrita, que pode facilitar bastante o processo de comunicação quando esses pacientes são alfabetizados na língua portuguesa. Tal método é bastante interessante, e poderia tornar-se um dos mais eficazes no processo da comunicação. No entanto, na maioria das vezes, esta técnica é inviável, pois muitos deficientes auditivos jamais freqüentaram a escola ou não foram instrumentalizados no alfabeto.

Ainda conforme observado, alguns profissionais não buscaram a comunicação direta com o deficiente auditivo, mas procuraram alguém que os intermediassem. Todavia, esse método nem sempre é eficaz, pois o paciente pode vir desacompanhado ao atendimento, ou então querer sigilo sobre sua consulta ou sobre o motivo da sua internação. Em relação a esse tipo de comunicação, não se sabe se o profissional não conhecia outra forma de comunicação ou se pou- pava seus esforços, seu tempo e sua criatividade. Consoante se verificou, não existe uma maneira unificada de comunicação capaz de abranger todas as situações envolvendo as pessoas com deficiência auditiva. Diante disto, compete ao profissional adequar a melhor forma à situação vivenciada.

No intuito de conhecer um pouco mais sobre o relacionamento dos profissionais de enfermagem com os deficientes auditivos, solicitou-se aos profissionais falar um pouco sobre esse relacionamento. As respostas foram enquadradas em duas subcategorias distintas: a de dificuldade no relacionamento e a de relacionamento satisfatório.

Como se percebeu a partir das falas, o relacionamento das enfermeiras com o deficiente auditivo é complicado, havendo bloqueio, aflição e angústia. Aquele que não ouve tão bem, ou não percebe algumas manifestações sonoras conforme deveria, em regra, passa a ser distinguido como alguém com uma perda, carência, ou deficiência ${ }^{(7)}$. Tal situação confirma a maneira própria de organização dos deficientes auditivos: vivem em grupos para se protegerem e se comunicarem sem dificuldade ${ }^{(16)}$.

Apesar de o deficiente auditivo ter suas limitações, não se deve tratá-lo, preconceituosamente, como um ser humano diferente. Ele deve ter os mesmos direitos das pessoas ditas normais. Além disso, suas limitações não podem impedir sua comunicação e seu relacionamento. Portanto, os profissionais precisam ser eficientes no desempenho do seu papel, melhorando sua relação com esse tipo de paciente. Depende de cada enfermeiro superar esse bloqueio e tratar essa questão do relacionamento com naturalidade.

Entretanto, assim como houve profissionais de difícil relacionamento com o deficiente auditivo, outros, em alguns casos, tiveram facilidade ou, pelo menos, conseguiram um relacionamento satisfatório. O estilo de relacionamento focalizado caracteriza-se pelo interesse, bem-estar do paciente e envolvimento bondoso, firme, cordial e com comprometimento emocional. Se os enfermeiros aprenderem a utilizar com mais propriedade outros veículos de comunicação, além da fala, sem dúvida alguma, favorecerão a comunicação com este grupo, especialmente por meio dos elementos não-verbais. Desse modo, o relacionamento se tornará eficaz ${ }^{(8)}$.

É importante enfatizar ainda que a dificuldade de relacionamento com os deficientes auditivos não é geral, pois alguns profissionais sempre tentam aprender maneiras de relacionar-se eficazmente, no intuito de proporcionar o bemestar e transmitir maior confiança. Todavia, como o conceito de relacionamento é mais amplo que o de comunicação, acaba englobando-a ${ }^{(20)}$. Pesquisa nessa temática revelou que a dificuldade de comunicação entre as pessoas ditas normais e as deficientes, em particular as auditivas, pode e precisa ser contornada ${ }^{(8)}$. Tal fato pode ser explicado por não conhecerem o conceito de relacionamento. 
A última categoria, Sugestões para melhorar a Comunicação, mencionada pelas enfermeiras, foi agrupada em melhor preparo profissional e maior divulgação da LIBRAS.

Na opinião das participantes, é indispensável um maior preparo dos enfermeiros já na sua formação acadêmica como uma disciplina obrigatória, ou a oferta de cursos e treinamentos nesse sentido, pois de acordo com os profissionais entrevistados não existe no decorrer da formação profissional nenhum preparo em relação a essa situação. Os próprios profissionais deveriam reconhecer essa carência e despreparo, e buscar meios para supri-los. Outra sugestão verbalizada pela categoria foi que deveria haver maior divulgação nos meios de comunicação sobre a humanização do atendimento e socialização dos deficientes auditivos. Neste grupo de sugestões ainda se ressaltou a necessidade de conhecer mais este tipo de deficiência com ênfase em palestras educativas e políticas públicas voltadas para este contexto, como também divulgação do alfabeto dos surdos.

Sabe-se que a LIBRAS tem-se integrado a práticas educacionais e a programas destinados a pessoas surdas, permitindo, dessa forma, o estabelecimento efetivo de contatos, até então, no mais das vezes, total ou parcialmente bloqueados $^{(5)}$. Demonstra-se, a partir daí, a importância de conhecer essa linguagem para se poder ter uma comunicação efetiva com pacientes deficientes auditivos ${ }^{(21)}$.

Apesar desse ponto não ter sido mencionado como forma de comunicação, mas apenas como sugestão para uma melhor comunicação, é válido notar que embora a maioria das profissionais não conheçam essa linguagem, elas percebem a sua importância, e demonstram interesse em aprender a LIBRAS para utilizá-la no futuro. Além disso, incluir a LIBRAS na grade curricular de cursos da área da saúde, pelo menos como uma disciplina optativa, minimizaria o problema e facilitaria o acesso dos deficientes auditivos aos serviços de saúde, garantindo um cuidado eficaz, de acordo com suas necessidades reais.

\section{REFERÊNCIAS}

1. Bolonhini Junior RB. Portadores de necessidades especiais: as principais prerrogativas dos portadores de necessidades especiais e a legislação brasileira. São Paulo: ARX; 2004.

2. Brasil. Ministério da Justiça. Programa de Ação Mundial para as Pessoas com Deficiência. Brasília: CORDE; 1996.

3. Fonseca V. Educação especial: Programa de Estimulação Precoce: uma introdução às idéias de Feuerstein. $2^{\mathrm{a}}$ ed. Porto Alegre: Artes Médicas; 1995.

4. Ferreira ABH. Novo dicionário Aurélio da língua portuguesa. Rio de Janeiro: Nova Fronteira; 1998.

\section{CONSIDERAÇÕES FINAIS}

O trabalho ora desenvolvido mostrou que existe despreparo das enfermeiras no domínio do processo de comunicação com deficientes auditivos. Em relação à percepção do processo de comunicação, todas se enquadraram no grupo com dificuldade de comunicação. As enfermeiras mostraram-se inseguras ao se relacionarem com os surdos por não conhecerem a língua utilizada por eles e pela falta de habilidade em transmitir a informação sobre sua saúde.

É importante enfatizar ainda que a dificuldade de relacionamento com os deficientes auditivos não é geral, pois alguns profissionais sempre tentam aprender maneiras de relacionar-se eficazmente, no intuito de proporcionar o bemestar e transmitir maior confiança. Essas profissionais evidenciaram seu esforço e a busca pela melhor forma de relacionamento com esse tipo de paciente, porém o sucesso é limitado pela falta de preparo desde a sua formação acadêmica.

$\mathrm{Na}$ tentativa de superar essa falha, foram citadas sugestões para aperfeiçoar as relações interpessoais entre as profissionais e as pessoas com deficiência auditiva. Entre estas sugestões constam: necessidade de maior preparo profissional, acrescido de ampla divulgação nos meios de comunicação da LIBRAS e ênfase do tratamento humanizado com os deficientes auditivos, com vistas a minimizar o preconceito em relação a esse tipo de paciente.

Como a deficiência auditiva atinge considerável parcela da população mundial, exigi-se particular atenção nesse sentido, pois muitos profissionais, independentemente de estarem ou não preparados, podem se deparar com essa situação. Para enfrentá-la com sucesso, é indispensável o interesse profissional pelo assunto e a adaptação nas grades curriculares de cursos da área da saúde em geral.

Dessa forma, amparado pelo conhecimento e pelo empenho no bem-estar do deficiente auditivo, o profissional poderá concretizar o processo de comunicação e garantir a este deficiente um cuidado eficaz, de acordo com suas necessidades.

5. Ciccone M. Comunicação total: introdução - estratégia - a pessoa surda. Rio de Janeiro: Cultura Médica; 1990.

6. França ISX. Formas de sociabilidade e instauração da auteridade: vivência dos portadores de deficiência [tese]. Fortaleza: Departamento de Enfermagem, Universidade Federal do Ceará; 2004.

7. Skliar C, organizador. A surdez: um olhar sobre as diferenças. Porto Alegre: Mediação; 1998.

8. Nogueira RA, Caetano JA, Pagliuca LMF. Interpretação da comunicação não-verbal de um grupo de surdos. Rev RENE. 2000;1(1):41-5. 
9. Silva MJP. Comunicação tem remédio: a comunicação nas relações interpessoais em saúde. $2^{\text {a }}$ ed. São Paulo: Gente; 1996.

10. Stefanelli MC, Carvalho EC, organizadoras. A comunicação nos diferentes contextos da enfermagem. Barueri: Manole; 2005.

11. Stefanelli MC. Comunicação com paciente: teoria e ensino. $2^{\mathrm{a}}$ ed. São Paulo: Robe; 1993.

12. Polit DF, Beck CT, Hungler BP. Fundamentos de pesquisa em enfermagem. $5^{\text {a }}$ ed. Porto Alegre: Artes Médicas; 2004.

13. Pagliuca LMF, França ISX, Moura ERF, Caetano JA, Macedo KNF, Vasconcelos LR, et al. Acessibilidade da pessoa portadora de deficiência física e/ou sensorial aos serviços de saúde: estudo das condições físicas e de comunicação [relatório de pesquisa]. Fortaleza: Departamento de Enfermagem, Universidade Federal do Ceará; 2004.

14. Bardin L. Análise de conteúdo. Lisboa: Edições 70; 1977.

15. Conselho Nacional de Saúde. Resolução n. 196, de 10 de outubro de 1996. Dispõe sobre diretrizes e normas regulamentadoras de pesquisa envolvendo seres humanos. Bioética. 1996;4(2 Supl):15-25.
16. Sousa RA, Pagliuca LMF. Cartilha sobre saúde sexual e reprodutiva para surdos como tecnologia emancipatória: relato de experiência. Rev RENE. 2001;2(2):80-6.

17. Sousa RA, Pagliuca LMF. Saúde sexual e reprodutiva para surdos: apreciação de uma metodologia educativa. Acta Paul Enferm. 2003;16(1):22-9.

18. Rosa CG, Barbosa MA, Bachion MM. Comunicação da equipe de enfermagem com deficientes auditivos com surdez severa: um estudo exploratório. Rev Eletrônica Enferm [periódico na Internet]. 2000 [citado 2005 abr. 20];2(3):[cerca de 10 p.]. Disponível em: http://www. fen.ufg.br/revista.

19. Rebouças CBA. Características da comunicação não-verbal entre o enfermeiro e o cego [dissertação]. Fortaleza: Departamento de Enfermagem, Universidade Federal do Ceará; 2005.

20. Orlando IJ. O relacionamento dinâmico enfermeiro/paciente: função, processo e princípios. São Paulo: EPU; 1978.

21. Chaveiro N, Barbosa MA. Assistência ao surdo na área de saúde como fator de inclusão social. Rev Esc Enferm USP. 2005;39(4):417-22. 